\title{
(2) OPEN ACCESS \\ Venous thrombosis via pulmonary arteriovenous malformation causing acute myocardial infarction in a relatively young female patient
}

\author{
China Goto, Shoichiro Yatsu 지 , Hideki Wada, Satoru Suwa
}

Department of Cardiovascular Medicine, Juntendo University Shizuoka Hospital, Izunokuni, Shizuoka, Japan

\section{Correspondence to}

Dr Shoichiro Yatsu:

syatsu@juntendo.ac.jp

Accepted 20 January 2022
Check for updates

(c) BMJ Publishing Group Limited 2022. Re-use permitted under CC BY-NC. No commercial re-use. See rights and permissions. Published by BMJ.

To cite: Goto C, Yatsu S, Wada $\mathrm{H}$, et al. BMJ Case Rep 2022:15:e247846. doi:10.1136/bcr-2021247846

\section{SUMMARY}

Pulmonary arteriovenous malformation (PAVM) is a probable cause of thromboembolic diseases such as acute myocardial infarction (MI); however, few cases have been reported. A woman in her early 40 s developed acute-onset chest pain; an ECG showed ST-elevated MI. Emergency catheter angiography showed that the culprit lesion was a thrombus that was treated successfully with aspiration. She had a history of deep venous thrombosis and CT revealed PAVM. It was likely that the venous thrombus had moved into the coronary artery through the PAVM. Catheter embolisation of the PAVM was performed and she did not experience any other cardiac event until 6 months after embolisation.

\section{BACKGROUND}

Pulmonary arteriovenous malformation (PAVM) is a rare vascular anomaly where abnormal anastomoses of the pulmonary arteries and veins occur. ${ }^{1}$ Most patients with PAVM are asymptomatic and remain undiagnosed until adulthood; however, PAVM has a direct right-to-left shunt and sometimes results in several severe comorbidities, such as chronic hypoxemia, rupture of the PAVM, central nervous system disorders and thromboembolic disease. ${ }^{1}$ Here, we report the case of a female patient who developed acute myocardial infarction (MI) with venous thrombosis via PAVM, in which a favourable outcome was obtained with catheter intervention.

\section{CASE PRESENTATION}

A woman in her early 40s with a history of deep vein thrombosis (DVT) and pulmonary embolism 2 years prior had experienced acute chest pain and dyspnoea while walking in the evening. The patient was transported to our hospital by ambulance. Her systolic blood pressure reading was $110-120 \mathrm{~mm}$ $\mathrm{Hg}$, and her routine medications were rivaroxaban $15 \mathrm{mg}$ once daily (maximum tolerated dose in Japan) for her medical history of DVT and pulmonary embolism, and a contraceptive pill. She had smoked 15-20 cigarettes per day for 22 years. She had no remarkable family history or other medical history, including coronary risks.

\section{INVESTIGATIONS}

Initially, she reported strong chest pain with cold sweat, restlessness and peripheral coldness. Her vital signs revealed cardiogenic shock, with a blood pressure of $84 / 52 \mathrm{~mm} \mathrm{Hg}$, heart rate of 62 beats

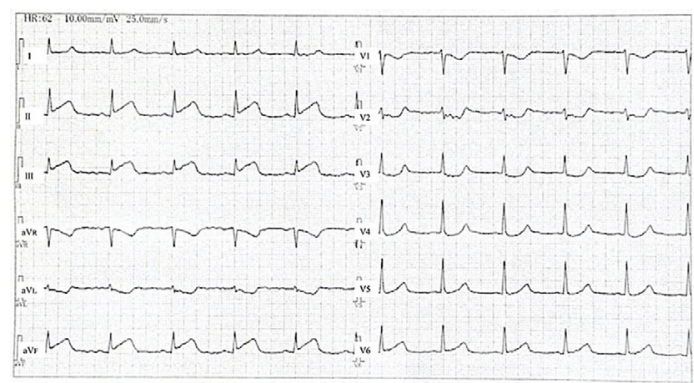

Figure 1 Electrocardiography on arrival. An ECG revealed sinus and ST-segment elevation in leads II, III and $\mathrm{aVF}$ with the reciprocal change of $\mathrm{aVL}$ and $\mathrm{V} 1-4$ on arrival in the hospital.

per minute, $\mathrm{O}_{2}$ saturation of $98 \%$ on room air and body temperature of $36.2^{\circ} \mathrm{C}$. An ECG showed sinus rhythm and ST-segment elevation in leads II, III and aVF with reciprocal changes in aVL and V1-4 (figure 1). Echocardiography revealed severe hypokinesis of the inferior wall. Thus, the patient was considered to have acute ST-elevated MI (STEMI).

\section{DIFFERENTIAL DIAGNOSIS}

Possible causes of ST-elevation with acute chest pain include MI, pericarditis, myocarditis, takotsubocardiomyopathy and pulmonary embolism.

In pericarditis, diffuse concave ST-elevation and pericardial effusion are common. Myocarditis also provides diffuse ST-elevation and is often preceded by fever and gastrointestinal symptoms. ST-elevation is rare in pulmonary embolism; however, severe desaturation, sinus tachycardia in electrocardiography and right heart strain in echocardiography are usually obtained. Takotsubo-cardiomyopathy shows takotsubo-like wall motion with ST-elevation

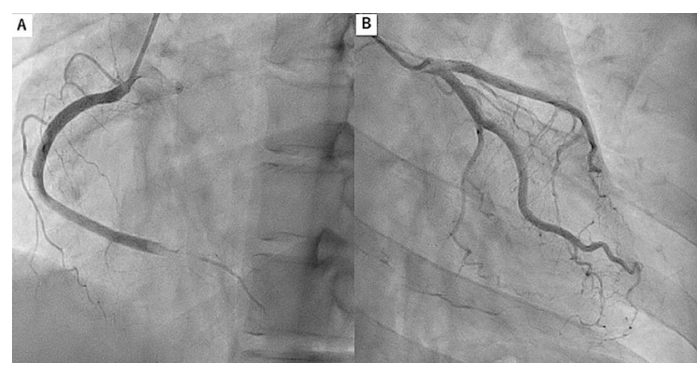

Figure 2 Emergent coronary angiography on arrival. Coronary angiography revealed $(A)$ occlusion of the distal right coronary artery and (B) no other obstructive lesions in the left coronary arteries. 


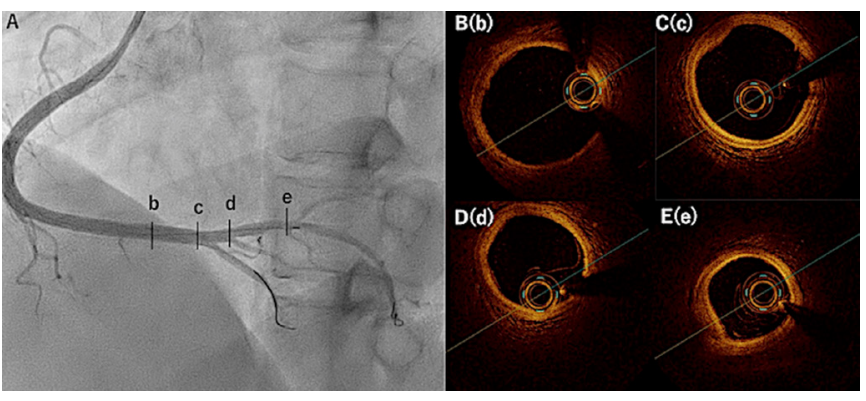

Figure 3 Coronary angiography and optical coherence tomography (OCT) after the aspiration. (A) Coronary angiography and (B-E) OCT findings showed no obstructive lesion after aspiration. (B-E) OCT revealed no plaque rupture, arteriosclerosis or erosion in the vascular lumen.

in echocardiography unless coronary obstruction has occurred. In this case, chest pain and dyspnoea were the main symptoms without fever and worsening oxygenation. The ECG and echocardiogram suggested ischaemia of the inferior wall. These findings were consistent with an acute inferior MI. Additionally, we had to rule out takotsubo-cardiomyopathy using coronary angiography for further investigation.

\section{TREATMENT}

Emergency coronary angiography showed occlusion of the distal right coronary artery (RCA) and no other obstructive lesions (figure 2). Aspiration was repeated on the culprit lesion of the RCA and blood clots were aspirated. The blood flow gradually improved and optical coherence tomography (OCT) was performed. OCT detected no plaque rupture, arteriosclerosis or erosion of the vascular lumen (figure 3). Additionally, the procedure was completed without stent use.

The patient's postoperative course was uneventful. Blood tests revealed no other abnormalities even during thrombophilia screening for Protein C and S antigens, antithrombin III activity and antiphospholipid antibodies (including anticardiolipin antibody and lupus anticoagulant). Contrast-enhanced CT showed a right PAVM (figure 4). Although DVT and pulmonary embolism were not detected on contrast CT at this time, her history of DVT and PAVM, smoking history and intake of contraceptive pills suggested that the thrombus had occluded the coronary artery through the PAVM from the venous system. We then performed percutaneous PAVM embolisation using the coiling technique and the PAVM was successfully blocked (figure 5).
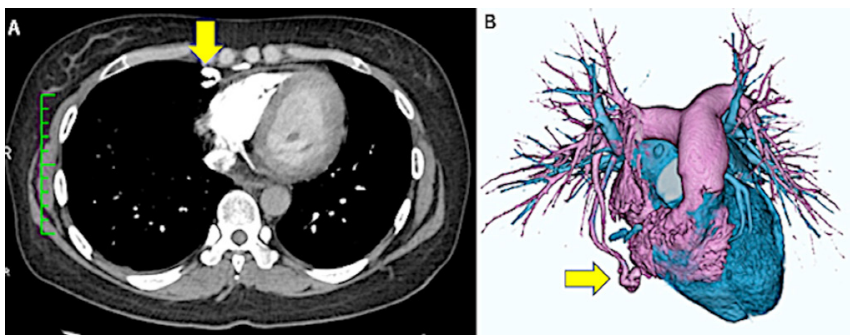

Figure 4 The right pulmonary arteriovenous malformation (PAVM) in enhanced CT. (A) Contrast CT of axial view and (B) 3D reconstruction revealed the right PAVM.

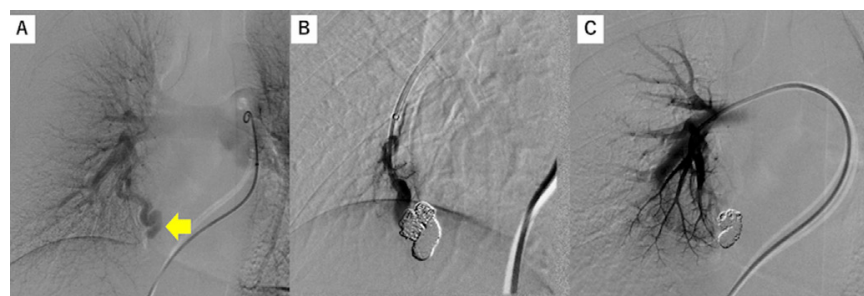

Figure 5 Pulmonary angiography and percutaneous pulmonary arteriovenous malformation (PAVM) embolisation. (A) Pulmonary angiography revealed a right PAVM and (B) percutaneous embolisation of PAVM was performed via the pulmonary artery. (C) Final angiography showed no significant shunt flow.

\section{OUTCOME AND FOLLOW-UP}

The patient's dyspnoea symptoms reduced after occlusion of the PAVM and she did not experience another event until the last follow-up, 6 months postoperatively.

\section{DISCUSSION}

This is a case of STEMI in a woman with PAVM and a history of venous thromboembolism (VTE). PAVM provides a direct rightto-left shunt, allowing the passage of paradoxical thrombotic embolisation. Such embolisation commonly presents as stroke or brain abscess; treatment of PAVMs is considered the standard of care to prevent these events. ${ }^{12}$ However, few paradoxical coronary artery embolisation cases via PAVM are reported. ${ }^{34}$ Here, we report a rare case of MI with PAVM that was treated only with aspiration and anticoagulation based on OCT findings.

According to a previous report, the mortality of untreated patients with PAVM was $11 \%$ after 6 years from diagnosis. ${ }^{5}$ In addition, PAVM is often associated with hereditary haemorrhagic telangiectasia (HHT). PAVM is present in $15 \%-50 \%$ of people with HHT and has been associated with life-threatening complications. $^{6}$ Although, we did not perform a genetic test in the present case because there were no symptoms, arteriovenous malformation and family history to suspect HHT. However, we would have considered the genetic test if she had any symptoms of HHT.

Embolisation using a catheter is the major treatment for PAVM. It is a safe and less invasive intervention with a high success rate of $98.7 \%$ and a low major complication rate of approximately $1 \% .{ }^{27}$ British Thoracic Society's clinical statement on PAVM also indicates that all patients with radiographically visible PAVM should be considered to receive embolisation treatment even for asymptomatic patients because PAVM treatment reduces the risk for paradoxical emboli and improves oxygenation, other physiological parameters, symptoms exacerbated by right-to-left shunting and haemorrhage. ${ }^{7}$ Moreover, the Cochrane Intervention Review of PAVM shows that based on observational studies, all PAVMs, irrespective of size, amenable to embolisation should be treated. ${ }^{8}$ We should consider PAVM embolisation when a PAVM is detected even if the patients are asymptomatic.

In the present case, the limitation is that DVT and pulmonary embolisation were not detected, and it is not possible to prove whether a venous thrombus caused the actual coronary artery occlusion or not. However, considering that the patient, a relatively young woman with little coronary risk, was at high risk for venous thrombosis due to a history of DVT and pill therapy and had PAVM, the cause of MI was highly likely venous thrombosis.

We encountered a rare case of a relatively young woman who developed acute MI from venous thrombosis via PAVM and was successfully managed with PAVM occlusion. PAVM might cause 
MI; thus, we might consider the possibility of PAVM if a patient with MI has a thrombotic lesion and no other significant coronary risk factors.

\section{Patient's perspective}

One day, I suddenly became distressed without any warning and was carried to the hospital by ambulance. I had experienced a pulmonary embolism before, but the pain this time was completely different from the last time. I appreciate the doctors and paramedical workers for treating me quickly. After the treatment, I have not experienced any further symptoms. I have heard that both myocardial infarction and pulmonary embolism may result in a fatal condition; hence, I intend to use this opportunity to review my lifestyle and prevent a recurrence.

\section{Learning points}

- Pulmonary arteriovenous malformation (PAVM) might cause various complications, including cerebrovascular and cardiovascular diseases.

- Catheter embolisation of PAVM should be considered to prevent thromboembolic comorbidities of PAVM, even in asymptomatic patients.

Contributors CG and SY cared for the patient and drafted the manuscript. HW and SS reviewed the manuscript and added their interpretation. All authors read and approved the final manuscript.

Funding The authors have not declared a specific grant for this research from any funding agency in the public, commercial or not-for-profit sectors.

Competing interests None declared.
Patient consent for publication Consent obtained directly from the patient(s).

Provenance and peer review Not commissioned; externally peer reviewed.

Open access This is an open access article distributed in accordance with the Creative Commons Attribution Non Commercial (CC BY-NC 4.0) license, which permits others to distribute, remix, adapt, build upon this work non-commercially, and license their derivative works on different terms, provided the original work is properly cited and the use is non-commercial. See: http://creativecommons.org/ licenses/by-nc/4.0/.

Case reports provide a valuable learning resource for the scientific community and can indicate areas of interest for future research. They should not be used in isolation to guide treatment choices or public health policy.

\section{ORCID iD}

Shoichiro Yatsu http://orcid.org/0000-0002-2624-2898

\section{REFERENCES}

1 Tellapuri S, Park HS, Kalva SP. Pulmonary arteriovenous malformations. Int I CardiovasC Imaging 2019;35:1421-8.

2 Gossage JR, Kanj G. Pulmonary arteriovenous malformations. A state of the art review. Am J Respir Crit Care Med 1998;158:643-61.

3 Kajander OA, Seppänen J, Sioris T, et al. Multiple pulmonary arteriovenous malformations presenting as an acute myocardial infarction. Am J Emerg Med 2009:27:1020.e5-1020.e7.

4 Clark K, Pyeritz RE, Trerotola SO. Angina pectoris or myocardial infarctions, pulmonary arteriovenous malformations, hereditary hemorrhagic telangiectasia, and paradoxical emboli. Am J Cardiol 2013;112:731-4.

5 Pollak JS, Saluja S, Thabet A, et al. Clinical and anatomic outcomes after embolotherapy of pulmonary arteriovenous malformations. J Vasc Interv Radiol 2006;17:35-45.

6 Faughnan ME, Palda VA, Garcia-Tsao G, et al. International guidelines for the diagnosis and management of hereditary haemorrhagic telangiectasia. J Med Genet 2011:48:73-87

7 Shovlin CL, Condliffe R, Donaldson JW, et al. British thoracic Society clinical statement on pulmonary arteriovenous malformations. Thorax 2017;72:1154-63.

8 CCT H, Kwan GNC, Evans-Barns H. Embolisation for pulmonary arteriovenous malformation. Cochrane Database Syst Rev 2018;1:1-16. doi:10.1002/14651858. CD008017.pub5

Copyright 2022 BMJ Publishing Group. All rights reserved. For permission to reuse any of this content visit

https://www.bmj.com/company/products-services/rights-and-licensing/permissions/

BMJ Case Report Fellows may re-use this article for personal use and teaching without any further permission.

Become a Fellow of BMJ Case Reports today and you can:

- Submit as many cases as you like

- Enjoy fast sympathetic peer review and rapid publication of accepted articles

- Access all the published articles

- Re-use any of the published material for personal use and teaching without further permission

Customer Service

If you have any further queries about your subscription, please contact our customer services team on +44 (0) 2071111105 or via email at support@bmj.com.

Visit casereports.bmj.com for more articles like this and to become a Fellow 